\title{
Telephone-Based Intervention
}

National Cancer Institute

\section{Source}

National Cancer Institute. Telephone-Based Intervention. NCI Thesaurus. Code C116528.

Any program that uses interactions over the telephone to alter, modify, or eliminate an

undesired behavior. 